\title{
Improvement of Learning Outcomes Theme Healthy Is Important Materials For The Human Blood Circulation System Through Project Based Learning (PJBL) Method In Class Va SDN Rejosari 03 Semarang City In 2020
}

\author{
Mursyidah Qonitat \\ SDN Rejosari 03 Kota Semarang \\ itaqonitat16@gmail.com
}

\section{Article History}

received 3/12/2020

revised $17 / 12 / 2020$

accepted 31/12/2020

\begin{abstract}
This study aims to improve the learning outcomes of the theme of healthy is important material for human blood circulation through the pjbl method in class VA students at SDN Rejosari 03 Semarang. The approach used in this research is classroom action research. The population in this study were students of class VA SD Negeri Rejosari 03 Semarang, totaling 27 students 11 boys and 16 girls. Data was collected by means of tests and observations. Tests are given to determine student learning outcomes, while observation aims to determine the difficulties experienced by students when solving problems given by the teacher. The conclusion of this study is that the learning outcomes of the healthy theme are important in the material of the human circulatory system through the pjbl method in class VA of SD Negeri Rejosari 03 Semarang, obtained in cycle 1 students who reached the KKM only found 15 from 27 students or $55.5 \%$ while cycle 2 students which reached the KKM as many as 25 from 27 students or $92.5 \%$.
\end{abstract}

Keywords: learning outcomes, blood circulation, project based learning

\begin{abstract}
Abstrak
Penelitian ini bertujuan meningkatkan hasil belajar tema sehat itu penting materi sistem peredaran darah manusia melalui metode pjbl pada siswa kelas VA SDN Rejosari 03 Semarang. Pendekatan yang digunakan dalam penelitian ini adalah penelitian tindakan kelas. Populasi dalam penelitian ini adalah siswa kelas VA SD Negeri Rejosari 03 Semarang yang berjumlah 27 siswa terdiri dari 11 orang laki-laki dan 16 orang perempuan. Pengumpulan data dilakukan dengan tes dan observasi. Tes diberikan untuk mengetahui hasil belajar siswa, sedangkan observasi bertujuan untuk mengetahui kesulitan yang dialami siswa saat menyelesaikan soal yang diberikan guru. Simpulan penelitian ini adalah hasil belajar tema sehat itu penting materi sistem peredaran darah manusia melalui metode $\mathrm{pjb} / \mathrm{di}$ kelas VA SD Negeri Rejosari 03 Semarang, diperoleh siklus 1 siswa yang mencapai kkm hanya berjumlah 15 siswa dari 27 siswa atau $55,5 \%$ sedangkan siklus 2 siswa yang mencapai kkm sebanyak 25 siswa dari 27 siswa atau 92,5\%.
\end{abstract}

Kata kunci : hasil belajar, peredaran darah, pembelajaran berbasis proyek

Social, Humanities, and Education Studies (SHEs): Conference Series https://jurnal.uns.ac.id/shes

p-ISSN 2620-9284

e-ISSN 2620-9292 


\section{PENDAHULUAN}

Dunia pendidikan memegang peranan penting bagi kelangsungan hidup suatu bangsa. Melalui pendidikan, generasi penerus bangsa yang berkualitas akan lahir dan menjadi pemimpin yang bertanggung jawab. Salah satu tujuan pendidikan nasional yang termaktub dalam Pembukaan Undang Undang Dasar 1945 alinea IV yaitu mencerdaskan kehidupan bangsa. Dalam rangka mencerdaskan kehidupan bangsa, pemerintah dan masyarakat diharuskan menyelenggarakan pendidikan. Dalam Undang-Undang Sistem Pendidikan Nasional Nomor 20 tahun 2003 Bab II Pasal 3, telah dirumuskan secara tegas mengenai dasar, fungsi, dan tujuan pendidikan nasional bahwa: "Pendidikan nasional berfungsi mengembangkan kemampuan dan membentuk watak serta peradaban bangsa yang bermartabat dalam rangka mencerdaskan kehidupan bangsa, bertujuan untuk berkembangnya potensi siswa agar menjadi manusia yang beriman dan bertaqwa kepada Tuhan Yang Maha Esa, berakhlak mulia, sehat, berilmu, cakap, kreatif, mandiri, dan menjadi warga negara yang demokratis serta bertanggungjawab".

Berdasarkan Undang-Undang tersebut, diketahui bahwa proses pendidikan nasional merupakan dasar bagi pembangunan suatu bangsa yang muaranya pada pembentukan akhlak mulia serta bermartabat. Undang-Undang Sistem Pendidikan Nasional No. 20 Tahun 2003 Bab II Pasal 2 Ayat 19 menyebutkan bahwa "kurikulum adalah seperangkat rencana dan pengaturan mengenai tujuan, isi, dan bahan pelajaran serta cara yang digunakan sebagai pedoman penyelenggaraan kegiatan pembelajaran untuk mencapai tujuan pendidikan tertentu". Kurikulum senantiasa ditingkatkan mutunya, demikian pula kurikulum di Indonesia. Salah satu upaya yang ditempuh untuk meningkatkan mutu kurikulum tersebut diantaranya dengan melaksanakan penyempurnaan kurikulum.

Meningkatkan hasil belajar perlu dilaksanakan dengan serius mengingat masa pandemi Covid 19 seperti sekarang ini belum dapat dipastikan kapan berakhirnya. Dengan mempertimbangan keadaan yang demikian itu,perlu dilakukannya cara-cara yang efektif agar dapat meningkatkan hasil belajar melalui pembelajaran daring atau online. Penggunaan aplikasi-aplikasi pendidikan menjadi salah satu alternatif atau solusi yang digunakan sebagai alat dan media menyampaikan materi pembelajaran selama siswa belajar di rumah.

Berdasarkan pengamatan yang dilakukan oleh peneliti pada pelaksanaan pembelajaran tema sehat itu penting pada materi sistem peredaran darah manusia, guru kurang menggunakan model pembelajaran yang inovatif, guru kurang menggunakan media pembelajaran yang menarik, pembelajaran masih berpusat pada guru dan kurang melibatkan siswa. Hal tersebut menjadikan siswa selama proses pembelajaran kurang memperhatikan penjelasan guru, berbicara dengan teman karena baru mengenal zoom meeting saat pembelajaran. Permasalahanpermasalahan dalam pembelajaran tersebut berdampak pada hasil belajar siswa kelas VA SDN Rejosari 03 Kota Semarang. Dari data yang diperolah sebanyak 10 dari 27 siswa mendapatkan nilai di bawah kkm yaitu 70 .

Pembelajaran tema sehat itu penting materi sistem peredaran darah manusia pada kelas VA SDN Rejosari 03 Kota Semarang mengalami kendala pada pemahaman konsep.Kendala yang demikiuan membuat guru menggunakan metode Project Based Learning (PJBL) sebagai langkah untuk mengatasi kendala tersebut.Project Based Learning adalah metode pembelajaran yang menggunakan proyek/kegiatan sebagai media. Peserta didik melakukan eksplorasi, penilaian, interpretasi, sintesis, dan informasi untuk menghasilkan berbagai bentuk hasil belajar. Project based learning atau pembelajaran berbasis proyek merupakan model pembelajaran yang berpusat pada siswa untuk melakukan suatu investigasi yang mendalam terhadap suatu topik. Siswa secara konstruktif melakukan pendalaman 
pembelajaran dengan pendekatan berbasis riset terhadap permasalahan dan pertanyaan yang berbobot, nyata, dan relevan.

Dari ulasan latar belakang tersebut maka peneliti akan mengkaji melalui penelitian tindakan kelas dengan judul“ Peningkatan Hasil Belajar Tema Sehat itu Penting Materi Sistem Peredaran Darah Manusia Melalui Metode PJBL Pada Kelas VA SDN Rejosari 03 Kota Semarang Tahun 2020 “

\section{METODE}

Penelitian ini menggunakan pendekatan Penelitian Tindakan Kelas. (PTK). PTK merupakan bentuk penelitian tindakan yang diterapkan dalam aktivitas pembelajaran di kelas. Ciri khusus PTK adalah adanya tindakan nyata yang dilakukan sebagai bagian dari kegiatan penelitian dalam rangka memecahkan masalah pembelajaran di kelas (Muhammad Djajadi, S.Pd., M.Pd., Ph.D, 2019: 20)

Secara rinci prosedur penelitian tindakan ini dapat dijabarkan dalam 2 siklus. Prosedur pelaksanaan pembelajaran pada siklus II sama dengan siklus I yaitu diawali dari perencanaan, pelaksanaan tindakan, dan refleksi. Pada siklus II dilakukan oleh peneliti dan guru dengan berdasarkan pada hasil refleksi pada siklus I. Menurut Rochiati Wiriaatmadja (2005: 103), apabila perubahan yang bertujuan meningkatkan kualitas pembelajaran telah tercapai, atau apa yang diteliti telah menunjukkan keberhasilan, siklus dapat diakhiri.

\section{HASIL DAN PEMBAHASAN}

Penelitian ini dilaksanakan di SD Negeri Rejosari 03 Kota Semarang untuk meneliti hasil belajar siswa tema sehat itu penting materi sistem peredaran darah manusia melalui metode project based learning (PJBL). Setelah peneliti melaksanakan observasi di kelas VA SD Negeri Rejosari 03 Kota Semarang, peneliti melakukan persiapan dengan menyusun konsep pelaksanaan, membuat jadwal, dan tugas penelitian serta menyusun instrumen yang akan digunakan dalam penelitian. Setelah selesai pelaksanaan penelitian, peneliti menyusun laporan penelitian dengan menyusun laporan hasil penelitian tindakan kelas pada bulan Januari tahun 2020.

Hasil pengamatan aktivitas siswa selama mengikuti pembelajaran tema sehat itu penting materi peredaran darah manusia pada kondisi awal dapat dideskripsikan bahwa masih banyak peserta didik yang kurang ketertarikan pada aktivitas belajarnya sehingga kegiatan hasil pembelajaran yang dilakukan kurang maksimal. Dengan kata lain hasil belajar siswa dalam kelas tersebut masih rendah dengan rata-rata nilai 68,9 dan hanya 10 dari 27 siswa yang mencapai KKM atau tuntas dalam belajar. Jika diprosentasekan dalam prosentase ketuntasan belajar hanya 37\%. Selain itu siswa tampak kurang antusias dalam memperhatikan dan aktif dalam kegiatan belajar dengan baik terbukti masih banyak peserta didik yang kelihatan dalam mengikuti pembelajaran ini. Dapat dibuktikan pada hasil observasi yang menyatakan bahwa ratarata keaktifan siswa pra siklus hanya mencapai nilai 2,5. Siswa tampak kurang antusias karena seakan-akan tidak mengetahu apa yang seharusnya dikerjakan.

Dari sisi guru, kurang memberikan pengarahan kepada siswa untuk segera melakukan kegiatan memberikan tugas dalam mengarahkan siswa untuk menemukan kesulitan dalam belajarnya. Selanjutnya pada siklus 1 guru melakukan tindakan dengan menerapkan model projeck based learning (PJBL) untuk meningkatkan hasil belajar siswa. Pada siklus 1 ini terdapat perubahan baik dari hasil tes maupun observasi. Dari hasil tes menunjukkan hasil belajar siswa mengalami peningkatan yaitu 15 dari 27 siswa sudah memenuhi KKM atau tuntas dalam belajar. Prosentase ketuntasan pada siklus 1 mencapai $55,5 \%$.

pada siklus 2 guru merefleksi hasil pada penerapan tindakan dengan menerapkan model project based learning (PJBL) siklus 1 kemudian merencanakan dan melakukan perubahan sehingga meningkatkan hasil belajar siswa. Pada siklus 2 
ini terdapat perubahan yang signifikan baik dari hasil tes maupun observasi. Dari hasil tes menunjukkan hasil belajar siswa mengalami peningkatan secara signifikan yaitu 25 dari 27 siswa sudah memenuhi KKM atau tuntas dalam belajar. Prosentase ketuntasan pada siklus 1 mencapai $92,5 \%$.

Selanjutnya, aktivitas siswa selama mengikuti pembelajaran tema sehat itu penting materi peredaran darah manusia dapat disajikan pada tabel berikut :

Tabel 1. Hasil belajar siklus 1 tema sehat itu penting materi sistem peredaran darah manusia melalui metode pbl siswa di Kelas V SD Negeri Rejosari 03 Kota Semarang

\begin{tabular}{|c|c|c|c|}
\hline No & Nama Siswa & Nilai Tes & Keterangan \\
\hline 1. & Siswa 01 & 80 & Tuntas \\
\hline 2. & Siswa 02 & 70 & Tidak Tuntas \\
\hline 3. & Siswa 03 & 80 & Tuntas \\
\hline 4. & Siswa 04 & 85 & Tuntas \\
\hline 5. & Siswa 05 & 65 & Tidak Tuntas \\
\hline 6. & Siswa 06 & 70 & Tidak Tuntas \\
\hline 7. & Siswa 07 & 65 & Tidak Tuntas \\
\hline 8. & Siswa 08 & 85 & Tuntas \\
\hline 9. & Siswa 09 & 90 & Tuntas \\
\hline 10. & Siswa 10 & 55 & Tidak Tuntas \\
\hline 11. & Siswa 11 & 80 & Tuntas \\
\hline 12. & Siswa 12 & 70 & Tidak Tuntas \\
\hline 13. & Siswa 13 & 70 & Tidak Tuntas \\
\hline 14. & Siswa 14 & 85 & Tuntas \\
\hline 15. & Siswa 15 & 95 & Tuntas \\
\hline 16. & Siswa 16 & 95 & Tuntas \\
\hline 17. & Siswa 17 & 85 & Tuntas \\
\hline 18. & Siswa 18 & 70 & Tidak Tuntas \\
\hline 19. & Siswa 19 & 70 & Tidak Tuntas \\
\hline 20. & Siswa 20 & 85 & Tuntas \\
\hline 21. & Siswa 21 & 50 & Tidak Tuntas \\
\hline 22. & Siswa 22 & 70 & Tidak Tuntas \\
\hline 23. & Siswa 23 & 85 & Tuntas \\
\hline 24. & Siswa 24 & 95 & Tuntas \\
\hline 25. & Siswa 25 & 85 & Tuntas \\
\hline 26. & Siswa 26 & 75 & Tuntas \\
\hline & Siswa 27 & 65 & Tidak Tuntas \\
\hline & Rata-rata & & 76,8 \\
\hline
\end{tabular}

Berdasarkan nilai KKM yang telah ditetapkan di kelas V SD Negeri Rejosari 03 Kota Semarang sebesar 70. Menunjukkan bahwa hasil belajar siswa pada materi sistem peredaran darah siswa kelas VA SD Negeri Rejosari 03 Kota Semarang menunjukkan 12 siswa belum mencapai $\mathrm{KKM}$, hanya 15 siswa yang sudah tuntas dalam pembelajaran dengan prosentase ketuntasan $55,5 \%$ 
Tabel 2. Uraian pencapaian Hasil belajar siklus 1 tema sehat itu penting materi sistem peredaran darah manusia melalui metode pjbl siswa di Kelas V SD Negeri Rejosari 03 Kota Semarang

\begin{tabular}{clc}
\hline No. & \multicolumn{1}{c}{ Uraian Pencapaian Hasil } & Hasil \\
\hline 1 & Uraian Pencapaian Hasil & 27 \\
2 & Jumlah peserta didik mendapatkan nilai < 70 & 12 \\
\cline { 2 - 3 } 3 & Jumlah peserta didik mendapatkan nilai $>70$ & 15 \\
4 & Rerata kemampuan pemahaman terhadap materi Peredaran & 76,8 \\
5 & Darah & $55,5 \%$ \\
\hline
\end{tabular}

Tabel 3. Hasil belajar siklus 2 tema sehat itu penting materi sistem peredaran darah manusia melalui metode PJBL siswa di kelas V SD Negeri Rejosari 03 Kota Semarang

\begin{tabular}{|c|c|c|c|}
\hline No & Nama Siswa & Nilai Tes & Keterangan \\
\hline 1. & Siswa 01 & 85 & Tuntas \\
\hline 2. & Siswa 02 & 80 & Tuntas \\
\hline 3. & Siswa 03 & 90 & Tuntas \\
\hline 4. & Siswa 04 & 90 & Tuntas \\
\hline 5. & Siswa 05 & 75 & Tuntas \\
\hline 6. & Siswa 06 & 80 & Tuntas \\
\hline 7. & Siswa 07 & 75 & Tuntas \\
\hline 8. & Siswa 08 & 85 & Tuntas \\
\hline 9. & Siswa 09 & 95 & Tuntas \\
\hline 10. & Siswa 10 & 70 & Tidak Tuntas \\
\hline 11. & Siswa 11 & 85 & Tuntas \\
\hline 12. & Siswa 12 & 80 & Tuntas \\
\hline 13. & Siswa 13 & 75 & Tuntas \\
\hline 14. & Siswa 14 & 90 & Tuntas \\
\hline 15. & Siswa 15 & 100 & Tuntas \\
\hline 16. & Siswa 16 & 100 & Tuntas \\
\hline 17. & Siswa 17 & 85 & Tuntas \\
\hline 18. & Siswa 18 & 75 & Tuntas \\
\hline 19. & Siswa 19 & 80 & Tuntas \\
\hline 20. & Siswa 20 & 85 & Tuntas \\
\hline 21. & Siswa 21 & 65 & Tuntas \\
\hline 22. & Siswa 22 & 80 & Tuntas \\
\hline 23. & Siswa 23 & 85 & Tuntas \\
\hline 24. & Siswa 24 & 95 & Tuntas \\
\hline 25. & Siswa 25 & 85 & Tuntas \\
\hline 26. & Siswa 26 & 75 & Tuntas \\
\hline 27. & Siswa 27 & 80 & Tidak Tuntas \\
\hline \multicolumn{2}{|c|}{ Rata-rata } & & \\
\hline
\end{tabular}

Berdasarkan nilai KKM yang telah ditetapkan di kelas $V$ SD Negeri Rejosari 03 Kota Semarang sebesar 70. Menunjukkan bahwa pada siklus 2 hasil belajar siswa 
pada materi sistem peredaran darah siswa kelas VA SD Negeri Rejosari 03 Kota Semarang menunjukkan hanya 2 siswa belum mencapai KKM, 25 siswa sudah tuntas dalam belajar dengan prosentase ketuntasan $92,5 \%$.

Tabel 4 .Uraian pencapaian Hasil belajar siklus 1 tema sehat itu penting materi sistem peredaran darah manusia melalui metode pbl siswa di Kelas $\mathrm{V}$ SD Negeri Rejosari 03 Kota Semarang

\begin{tabular}{clc}
\hline No. & \multicolumn{1}{c}{ Uraian Pencapaian Hasil } & Hasil \\
\hline 1 & Uraian Pencapaian Hasil & 27 \\
2 & Jumlah peserta didik mendapatkan nilai $<70$ & 2 \\
3 & Jumlah peserta didik mendapatkan nilai $>70$ & 25 \\
4 & Rerata kemampuan pemahaman terhadap materi Peredaran & 83,1 \\
& Darah & \\
5 & Persentase Ketuntasan Klasikal & $92,5 \%$ \\
\hline
\end{tabular}

Tabel 5. Rata-rata nilai siswa kelas VA SDN Rejosari 03

\begin{tabular}{lccc}
\hline \multirow{2}{*}{ Aspek } & \multicolumn{3}{c}{ Skor Rata-rata } \\
\cline { 2 - 4 } & Pra siklus & Siklus 1 & Siklus 2 \\
\hline Nilai tes & 68,9 & 76,8 & 83,1 \\
Nilai observasi & 2,5 & 3,25 & 3,75 \\
\hline
\end{tabular}
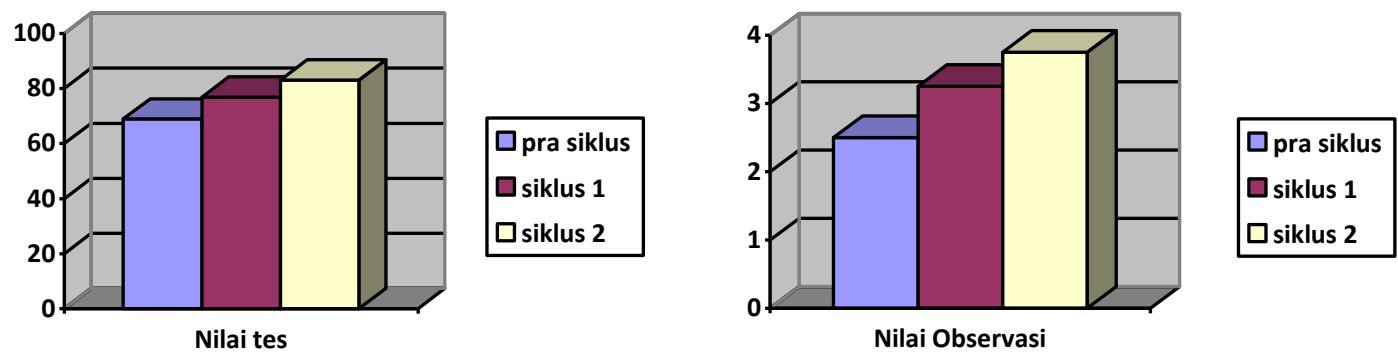

Gambar 1. Hasil belajar siswa kelas VA SDN Rejosari 03

\section{SIMPULAN}

Berdasarkan hasil penelitian pada peningkatan hasil belajar tema sehat itu penting materi sistem peredaran darah manusia melalui metode pjbl di kelas VA SDN Rejosari 03 Semarang diperoleh data sebagai berikut:

Pada siklus I terdapat peningkatan dari 10 siswa menjadi 15 siswa dari 27 siswa yang telah mencapai kriteria ketuntasan minimal sedangkan 12 siswa siswa yang belum mencapai batas kriteria ketuntasan minimal dengan prosentase ketuntasan klasikal 55,5\% dengan rata-rata kelas 76,8.

Pada siklus II lebih meningkat secara signifikan yaitu terdapat 25 siswa yang telah mencapai kriteria ketuntasan minimal dan hanya 2 siswa yang belum mencapai batas kriteria ketuntasan minimal dengan prosentase ketuntasan klasikal 92,5\% dengan rata-rata kelas 83,1 . 


\section{DAFTAR PUSTAKA}

Kemendikbud.2013. Materi Pelatihan Guru Implementasi Kurikulum 2013.Jakarta: Badan Pengembangan Sumber Daya Manusia Pendidikan dan Kebudayaan dan Penjaminan Mutu Pendidikan

Kristianti, Yulita diah. 2016. Model Pembelajaran Berbasis Proyek (Project Based Learning Model) Pada Pembelajaran Fisika Disma. Jurnal Pembelajaran Fisika. Vol. 5 No. 2, September 2016: hal $122-128$

Susanto, Ahmad. 2013. Teori Belajar Dan Pembelajaran Di Sekolah Dasar. Jakarta: Kencana Prenada Media Group.

Rifa'l, Achmad dan Catharina Tri Anni. 2009. Psikologi Pendidikan. Semarang: Universitas Negeri Semarang Press

Riyanto, Yatim.2010. Padigma Baru Pembelajaran: Sebagai Referensi bagi Pendidik dalam Implementasi Pembelajaran yang Efektif dan Berkualitas. Jakarta: Kencana

Widoyoko, Eko Putro. 2014. Penilaian Hasil Pembelajaran Di Sekolah. Yogyakarta. Pustaka Pelajar. 